\title{
The Impact of the COVID-19 "Infodemic" on Well-Being: A Cross-Sectional Study
}

\author{
Iffat Elbarazi $\mathbb{D}^{1, *}$, Basema Saddik $\mathbb{D}^{2,3, *}$, Michal Grivna', Faisal Aziz ${ }^{4}$, Deena Elsori ${ }^{5}$, Emmanuel Stip ${ }^{6}$, \\ Enes Bendak ${ }^{7}$ \\ 'Institute of Public Health, College of Medicine and Health Sciences, United Arab Emirates University, Al Ain, United Arab Emirates; ${ }^{2}$ Department of \\ Family and Community Medicine, College of Medicine, University of Sharjah, Sharjah, United Arab Emirates; ${ }^{3}$ Sharjah Institute for Medical Research, \\ University of Sharjah, Sharjah, United Arab Emirates; ${ }^{4}$ Interdisciplinary Metabolic Medicine Trials Unit, Division of Endocrinology and Diabetology, \\ Medical University of Graz, Graz, Austria; ${ }^{5}$ College of Health Sciences, Abu Dhabi University, Abu Dhabi, United Arab Emirates; ${ }^{6}$ Department of \\ Psychiatry, College of Medicine and Health Sciences, United Arab Emirates University, Al Ain, United Arab Emirates; ${ }^{7}$ ENPI, Dubai, United Arab \\ Emirates \\ *These authors contributed equally to this work
}

Correspondence: Iffat Elbarazi, Institute of Public Health, College of Medicine and Health Sciences, United Arab Emirates University, PO Box I555I, Al Ain, United Arab Emirates, Email ielbarazi@uaeu.ac.ae

Introduction: The COVID-19 pandemic created a crisis in the world of information and digital literacy. The amount of misinformation surrounding COVID-19 that has circulated through social media (SM) since January 2020 is notably significant and has been linked to rising levels of anxiety and fear amongst SM users.

Aim: This study aimed to assess SM practices during COVID-19 and investigated their impact on users' well-being.

Methods: An online survey was distributed between June 10 and July 312020 via different SM platforms in the United Arab Emirates and other Arabic-speaking countries. Adults above 18 years of age who spoke Arabic or English were invited to complete the survey which covered multiple domains, use and practices related to social media platforms and mental health questions, including the WHO-5 Well-Being Index.

Results: Out of 993 participants, 73\% were females, 76\% were non-Emirati, $91 \%$ were university graduates, and $50 \%$ were employed in various occupations, of which $20 \%$ were health care professionals. Participants indicated that they acquired COVID-19 related information primarily from social media and messaging applications of which WhatsApp was the most used. Most participants reported sharing information after verification. The mean well-being score was $12.6 \pm 5.6$, with $49 \%$ of participants reporting poor well-being (WHO-5 score <12.5). Adjusted linear regression showed that Facebook usage was negatively associated with well-being scores. Additionally, high time use was associated with poorer well-being. When adjusting for other factors, including low confidence in information around COVID-19 and poor knowledge overall, SM usage was significantly associated with poorer well-being.

Conclusion: The study sheds light on the use of SM during the pandemic and its impact on well-being throughout the novel coronavirus pandemic. Social media practices during emergencies and disasters may impact public well-being. Authorities are advised to step in to minimize the spread of misinformation and more frequent use of social media as it may influence well-being. Public health specialists, information technology and communication experts should collaborate to limit the infodemic effect on communities.

Keywords: COVID-19, infodemic, social media, WHO-5 Well-Being Index, internet use, mental health

\section{Article Summary}

To the best of our knowledge, this research is one of the earliest to investigate social media practices during the pandemic and their possible impact on well-being using the WHO-5 Well-Being Index (WHO-5) score. Results from an online study distributed in the United Arab Emirates and other Arabic speaking countries through SurveyMonkey has revealed a potentially negative relationship between social media use and general well-being, with most participants scoring "poor" well-being. The study findings indicate that people are using social media to access and share information related to COVID-19, claiming that they verify the information before sharing. This study highlights the possible effect of social 
media on well-being during this pandemic and other future crises. Therefore, global and local health authorities should be better equipped with strategies and interventions to tackle these issues in the future. However, further studies, including control group will be needed to investigate how social media practices directly impact well-being.

\section{Introduction}

An outbreak of the severe acute respiratory syndrome coronavirus 2 (SARS-CoV-2) appeared in Wuhan, China, leading to the emergence of a coronavirus disease 2019 (COVID-19) pandemic in 2020 worldwide. ${ }^{1}$ Regional and local efforts and policies have been influential in curbing the spread of this pandemic in community and health care settings. ${ }^{2,3}$ The uncertainty associated with COVID-19 has led to excessive global circulation and the spread of messages, information, disinformation and misinformation about the pandemic, its prevention, causes, complications and effects through the internet and social media. ${ }^{4,5}$ As of the date of the preparation of this manuscript, misinformation and disinformation are still spreading, especially with the appearance of variants. False information typically revolve around the origins of COVID-19, its long-term effects and its influence on different groups such as the elderly and children, as well as prevention measures and available vaccines. ${ }^{5}$

Social media platforms are communication tools hosted on and accessed via the internet that allow users to selectively communicate with others and acquire information from user-generated content. ${ }^{6}$ It has become an excellent means for sharing information, including medical and health information. ${ }^{7}$ Reliance on social media to collect information and news has increased significantly over the last two decades and reached its peak with the emergence of the COVID-19 pandemic. $^{8}$

It is claimed that COVID-19 is the first true social media infodemic due to the accelerated rate of information and misinformation transmission around the globe, fuelling panic and fear within the global population. ${ }^{5}$ Consequently, the World Health Organization (WHO) issued a warning statement regarding the infodemic's impact on people's digital literacy, its effect on health literacy, and reactions to COVID-19. The WHO defined "infodemic" as "an overabundance of information - some accurate and some not-that makes it hard for people to find trustworthy sources and reliable guidance when they need it, and which involves outbreak response and an influx of information about the disease, its spread and prevention. ${ }^{5}$ This influx of information also dilutes the public's trust in official and verifiable sources and generates fear and panic due to unverified rumours and exaggerated claims. It has also promoted xenophobia and racism toward certain ethnic groups such as those of Chinese and East-Asian heritage. As well as having a tremendous psychological impact on general and vulnerable populations such as adolescents and youth overall., ${ }^{5-13}$

The internet, and specifically popular social media platforms such as Twitter, Instagram and Facebook, have been extensively used in the last two decades to analyse, detect, and forecast infections and epidemics, and to predict patterns of human behavior regarding health. ${ }^{4,16}$ Internet use is very much linked to behavior related to health information; users write posts concerning their health on different social media platforms, often seeking information and advice. Information epidemiology, known as Infodemiology, is a domain in health informatics designated as "the science of distribution and determinants of information in an electronic medium with the ultimate aim to inform public health and public policy". ${ }^{17-19}$ However, SM's role in disseminating information has proven beneficial for both society and authorities in managing the response to the pandemic. Social media use, frequency, and eHealth literacy were also associated with people adopting more preventive behaviors. ${ }^{4,20}$ It was also shown to improve information spread, health literacy levels, and changing perceptions and attitudes. ${ }^{21}$ Globally, people's reliance on their traditional support groups has seen a reduction due to them substituting it with digital communication to share and connect with others. However, this was shown to increase anxiety and mental health issues following sudden restrictions in how we socialize with others. ${ }^{12,14,17,22,23}$ Many studies have pointed to the impact of social media use on mental health. ${ }^{24-27}$ This link was augmented during the pandemic due to the widespread physical, social distancing and isolation, fear, panic, and sociopolitical and economic factors induced by the pandemic. ${ }^{28}$

According to the media dependency theory by Ball-Rokeach, during a critical public disruption, there is a fundamental necessity for information and sense-making by people; in the modern world, mass media is typically bestsuited to meet this need. ${ }^{29}$ During a crisis such as this pandemic, people choose social media platforms to seek information and share their opinions. ${ }^{13,30-33}$ Moreover, during the pandemic, misuse and political agendas were being 
pushed through social media. ${ }^{34}$ People tend to search for information to reduce the anxiety produced by the resulting ambiguity in a crisis event. ${ }^{32,33}$ Moreover, vulnerable groups are affected mentally mostly by the pandemic and tend to search social media platforms for information, especially Facebook. ${ }^{35,36}$ Schønning et al found that studies that have looked at positive and negative outcomes of social media use on mental health and wellbeing among adolescents are rare. In another study, the overall use of social media was not reported to have an impact on adolescents' well-being, however, it was reported that it made them feel better. Social media navigators use the platforms to express their sentiments, opinions, and feelings, which can be a relevant source of data for researching mental health. ${ }^{37}$ In a recent study, students were found to seek emotional support and improve their social belongingness through social media use. ${ }^{38}$ Fake news distribution and sharing information reached their peak during the Covid-19 pandemic. ${ }^{39,40}$ People's tendency to share "fake news" related to COVID-19 may depend on several factors and may be impacted by social media dependency and information-seeking needs. Understanding why people share fake news became the interest of many researchers worldwide during the pandemic. ${ }^{39}$ Evidence suggests that symptoms of anxiety, depression and self-reported stress are common psychological reactions to the COVID-19 pandemic and may affect sleep patterns and the general well-being of individuals. ${ }^{41,42}$

This study aims to explore social media practices and use during the COVID-19 pandemic and investigate the effect of social media on an individual's well-being. Moreover, this study explores the use of social media to seek knowledge about COVID-19, treatment, and prevention during the pandemic.

\section{Methods}

\section{Reporting Guidelines}

We followed the CHERRIES checklist for reporting results of web-based surveys ${ }^{45}$ (Table S1).

\section{Design and Study Participants}

A cross-sectional study design was used to conduct this research during the COVID-19 outbreak between June 10, 2020 and July 31, 2020. Study participants were adults aged 18 years and above, of both genders who spoke Arabic or English. Participants were invited using a distribution through the researchers' networks, social media and using snowball sampling techniques to complete the online survey hosted on the SurveyMonkey platform. ${ }^{46}$ The survey link was shared with participants via email, WhatsApp, Instagram, and Facebook in the UAE and other Arabic-speaking countries. We also invited Arabic speaking subjects who lived in western countries like (Australia, Canada, the United States and Europe).

Additionally, participants who completed the survey were asked to share the survey link with their contacts. The first page of the survey described the research objectives and assured participants of their anonymity and confidentiality. Only those who agreed to participate in the survey could initiate it by clicking "yes I agree to participate". Ethical approval was obtained from the Abu Dhabi University Institutional Review Board on May 16, 2020 (CHS-20-05-00014).

\section{Data Collection}

A questionnaire comprising 25 questions was developed to achieve the study's objectives. The questions were divided into four main sections: demographics, social media use and practices during the COVID-19 pandemic, impact of COVID-19 on health-related knowledge, and the overall well-being and impact of COVID-19 on mental health. Wellbeing was measured using the WHO-5 Well-Being Index ${ }^{44}$ and questions adapted from "Assessing mental health and psychosocial needs and resources toolkit for humanitarian settings" (section B). ${ }^{47}$ This paper presents data related to the WHO-5 Well-Being Index score and social media use.

\section{WHO-5 Well-Being Index Score}

The WHO-5 Well-Being Index (WHO-5) (Table S2) is a short global rating scale that measures subjective well-being. The WHO-5 questions (Table S2) include five items: i) "I have felt cheerful and in good spirits", ii) "I have felt calm and relaxed", iii) "I have felt active and vigorous", iv) "I woke up feeling fresh and rested" and v) "My daily life has been filled with things that interest me". Each item is scored from 0 to 5 . The total raw score ranges from $0-25$. The score is 
multiplied by four to achieve a score in percentage (\%), with 0 representing the worst imaginable well-being and 100 representing the best imaginable well-being. ${ }^{48}$ A cut-off score of 12.5 multiplied by four was used to differentiate between good and poor well-being in this study. The WHO Well-Being index is scored based on a cut-off score of 50 with a total raw score ranging from $0-25$ that is multiplied by four to give the final score, with 0 representing the worst imaginable well-being and 100 representing the best imaginable well-being. ${ }^{43}$ We used the cut-off score of 12.5 multiplied by 4 out of 25 to be the score used in this study as used in other literature. ${ }^{49}$

\section{Social Media Platforms and Messaging Applications}

The most commonly used social media platforms and messaging applications globally and in the region were included in this study. These included WhatsApp, Facebook, Snapchat, Twitter, Instagram, LinkedIn, YouTube and Reddit. Whilst WhatsApp, Instagram, and Facebook are all grouped under Facebook, Inc., WhatsApp is a messaging platform. It differs in format from Instagram and Facebook, whereas the latter two function via user posts on an algorithmically served timeline. However, all of these platforms are generally used to share information. Regardless of the social media platform used, information on these tools might be accepted and shared without validation and adequate supervision from authorities on content. ${ }^{20}$

Previous studies have classified the WhatsApp and Snapchat messaging applications under social media platforms. ${ }^{36,50}$ Therefore, we decided to include them in our study as also being social media platforms yet refer to them as messaging applications. The questionnaire was developed in English, translated to Arabic, and - back translated to ensure translation accuracy and validity. The questionnaire was piloted among 25 students and health care professionals to ensure face and content validity. The survey was also sent to five public health experts to assess content validity and to ensure that survey questions assessed the constructs being measured. No modifications were made based on the pilot testing. The underlying constructs, "types of social media", "practices of looking for information", and "attitudes and beliefs in abilities and knowledge of social media", showed moderate to high levels of internal consistency with Cronbach's alpha of $0.744,0.688$ and 0.791 respectively.

The survey was distributed mainly in the UAE and through social media and to other Arabs in other countries. Only one survey entry was allowed from the same IP address to avoid multiple participant entries.

\section{Sampling}

The minimum required sample size was calculated as being 384 adults considering a $95 \%$ confidence level, a margin error of $5 \%$, and a power of $80 \%$. However, to account for low response rate attrition and sensitivity analysis, we increased our sample size by $60 \%$, making the minimum required sample 615 participants.

\section{Statistical Analysis}

Data were extracted in Microsoft Excel and analyzed in Stata version 16.0. ${ }^{48}$ Qualitative variables were tabulated as frequencies with corresponding percentages (\%) and quantitative variables as mean with corresponding standard deviations $( \pm \mathrm{SD})$. The overall well-being score was computed by summing up WHO-5 questions and further categorized into poor $(<12.5)$ and good well-being $(\geq 12.5)$. Unpaired t-tests and one-way analysis of variance (ANOVA) tests were applied to compare the mean well-being score with qualitative variables as appropriate. Chi-square or Fisher Exact tests were applied to compare well-being status with qualitative variables as appropriate. The $p$-value $<0.05$ was chosen to determine statistical significance. Simple and multiple linear regression was applied to assess the association of wellbeing score with social media use. In simple linear regression, crude estimates $(\beta)$ of well-being score with social media use were reported with corresponding 95\% confidence intervals (CI) and p-values. In multiple regression, the well-being score with each question related to social media use was adjusted for age, sex, marital status, education, nationality, and job. Upon initial analysis, we found no significant difference in well-being score among participants from different nationalities and countries and no differences in terms of social media practices and use. To ensure comparisons were meaningful and statistically appropriate, the responses "disagree" and "strongly disagree" and 'agree' and 'strongly agree' were merged. 


\section{Results}

\section{Demographics}

A total of 999 responses were collected. Only six surveys were returned incomplete and were excluded from the analysis (Table 1). The majority of study participants were females (73\%) with a mean age of $34 \pm 12.2$ years. Most participants had either undergraduate or post-graduate education. Almost three-quarters of the participants were nonEmiratis (76\%), with (64\%) residing in the UAE. Half of the participants (50\%) reported that they were working. Of those employed, the majority were health care professionals, followed by professionals in the education sector and academia.

\section{Sources of Information and Frequency of Use}

The majority of participants (72.3\%) reported using social media platforms as a main source of information for COVID19. Television was the third most commonly used tool for information on COVID-19, while newspapers, radio and scientific publications were less commonly used as sources of information (Figures 1). WhatsApp was reported as the most commonly used social media platform and was reportedly used for at least 1-3 hours a day (39.2\%) (Figures 2). While most participants reported using Snapchat, Twitter, Instagram, and YouTube between 1-5 hours a day on average (Table 2). The least used platforms by participants were Reddit ( $91.2 \%$ do not use) and LinkedIn ( $71.2 \%$ do not use). Almost half of the respondents reported using the internet to access information about COVID-19.

\section{Social Media Practices and Frequency of Use}

When asked about sharing information about COVID-19, 86\% of participants claimed they validated information before sharing. In contrast, $62 \%$ reported they felt responsible for sharing knowledge. Moreover, $78 \%$ stated that they felt confident in their abilities to differentiate between false and correct information about COVID-19 and 65\% agreed that they would send back comments or advice to the sender if they felt that information was dubious. Only $4.1 \%$ felt that their health-related knowledge and awareness had not increased due to the pandemic, while $17 \%$ had no opinion.

\section{Well-Being Score and Comparison with Other Variables}

Overall, almost half (51.5\%) of participants in this study scored above average in the WHO well-being score (Table S3). Further analysis was performed to compare between sociodemographic factors and well-being scores, social media use and well-being scores. It was found that being a non-Emirati and a blue-collar worker was negatively associated with well-being score ( $\leq 0.001$ and $\mathrm{P}=0.03$ ) respectively (Table 1$)$. At the same time, non-Facebook users had significantly higher well-being scores than Facebook users ( $\mathrm{p} \leq 0.001$ ) (Table 3). Additionally, participants who felt confident with their ability to differentiate between false and correct information and those who were likely to inform the sender of dubious information had significantly higher well-being scores $(\mathrm{p} \leq 0.001$ and $\mathrm{p}=0.027)$ (Table 4). Furthermore, participants who indicated an increase in knowledge and awareness of health-related information due to the COVID-19 pandemic reported higher well-being scores $(\mathrm{p}=0.005)$ (Table 3).

\section{Regression Analysis of Social Media Use with Well-Being Scores}

Simple and multiple linear regression analysis of well-being scores with social media use showed that Facebook use was a significant predictor of well-being score even after adjusting for covariates (Table 5). More use significantly predicted lower well-being scores, with $1-3$ hours use compared to no use $(\beta=-1.53,95 \% \mathrm{CI}=-2.79--0.27, \mathrm{p}=0.017)$ and over 5 hours use $(\beta=-0.32,95 \% \mathrm{CI}=-5.78--0.55, \mathrm{p}=0.018)$ than no use. Similarly, the use of Reddit for less than one hour predicted lower well-being scores than no use $(\beta=-2.24,95 \% \mathrm{CI}=-3.98--0.51, \mathrm{p}=0.011)$. Additionally, often looking up COVID-19 information and updates predicted lower well-being scores $(\beta=-2.99,95 \%$ CI $-5.03-0.95, \mathrm{p}=0.004)$. An increase in knowledge and awareness of health-related issues due to the COVID-19 pandemic did not remain a significant predictor of well-being scores after adjusting for covariates $(\beta=0.69,95 \% \mathrm{CI}=-0.47--1.86, \mathrm{p}=0.244)$. 
Table I Demographic Characteristics and Comparison with Well-Being Scores

\begin{tabular}{|c|c|c|c|c|c|c|}
\hline Variable & All & $\begin{array}{l}\text { Well-Being } \\
\text { Score }\end{array}$ & P-value* & $\begin{array}{l}\text { Good Well-Being } \\
(\geq \mid \mathbf{2 . 5})\end{array}$ & $\begin{array}{l}\text { Poor Well-Being } \\
(<12.5)\end{array}$ & P-value* \\
\hline Overall & 993 & $12.6 \pm 5.6$ & - & $5 I I(5 I .5)$ & $48 \mid(48.5)$ & - \\
\hline Age, Mean \pm SD & $34.2 \pm 12.2$ & $-0.02^{!}$ & 0.581 & $34.1 \pm 12.1$ & $34.3 \pm 12.4$ & 0.813 \\
\hline \multicolumn{7}{|l|}{ Age groups, n (\%) } \\
\hline$<20$ years & $88(8.9)$ & $12.8 \pm 4.8$ & 0.344 & $42(47.7)$ & $46(52.3)$ & 0.602 \\
\hline 20-29 years & $320(32.3)$ & $12.6 \pm 5.3$ & & $160(50.0)$ & $160(50.0)$ & \\
\hline $30-39$ years & $252(25.5)$ & $13.2 \pm 5.9$ & & III (44.I) & $|4|$ (55.9) & \\
\hline 40-49 years & $194(19.6)$ & $12.1 \pm 5.6$ & & $98(50.5)$ & $96(49.5)$ & \\
\hline $50+$ years & $136(13.7)$ & $12.5 \pm 6.1$ & & $68(50.0)$ & $68(50.0)$ & \\
\hline \multicolumn{7}{|l|}{ Sex, n (\%) } \\
\hline Female & $726(73.2)$ & $12.5 \pm 5.5$ & 0.119 & $36 I$ (49.7) & $365(50.3)$ & 0.063 \\
\hline Male & $266(26.8)$ & $13.1 \pm 5.7$ & & $150(56.4)$ & $116(43.6)$ & \\
\hline \multicolumn{7}{|l|}{ Education, n (\%) } \\
\hline Primary & $7(0.7)$ & $13.1 \pm 9.2$ & 0.060 & $4(57.1)$ & $3(42.9)$ & 0.074 \\
\hline Secondary & $80(8.1)$ & $12.3 \pm 5.7$ & & $4 \mid(5 I .3)$ & $39(48.7)$ & \\
\hline Undergraduate & $469(47.3)$ & $12.2 \pm 5.4$ & & $222(47.3)$ & $247(52.7)$ & \\
\hline Postgraduate & $436(43.9)$ & $13.2 \pm 5.7$ & & $244(56.0)$ & $192(44.0)$ & \\
\hline \multicolumn{7}{|l|}{ Marital status, n (\%) } \\
\hline Single & $448(45.2)$ & $12.5 \pm 5.2$ & 0.429 & $226(50.5)$ & $222(49.5)$ & 0.636 \\
\hline Married & 495 (49.9) & $12.8 \pm 5.8$ & & $263(53.1)$ & $232(46.9)$ & \\
\hline Divorced & $39(3.9)$ & $11.9 \pm 6.3$ & & $17(43.6)$ & $22(56.4)$ & \\
\hline Widow(er) & $10(1.0)$ & $10.5 \pm 7.0$ & & $5(50.0)$ & $5(50.0)$ & \\
\hline \multicolumn{7}{|l|}{ Nationality, n (\%) } \\
\hline Emirati & $180(23.1)$ & $14.1 \pm 5.2$ & $<0.001$ & $295(49.3)$ & $304(50.7)$ & $<0.001$ \\
\hline Non-Emirati & $599(76.9)$ & $12.4 \pm 5.6$ & & $115(63.9)$ & $65(36.1)$ & \\
\hline \multicolumn{7}{|c|}{ Country of Residence, n (\%) } \\
\hline UAE & $644(64.9)$ & $12.6 \pm 5.6$ & 0.519 & $337(52.3)$ & $307(47.7)$ & 0.189 \\
\hline Saudi Arabia & $112(11.3)$ & $13.4 \pm 5.4$ & & $64(57.1)$ & $48(42.9)$ & \\
\hline Lebanon & $88(8.9)$ & $11.6 \pm 6.2$ & & $33(37.5)$ & $55(62.5)$ & \\
\hline Egypt & $27(2.7)$ & $12.2 \pm 5.9$ & & 14 (5।.9) & $13(48.1)$ & \\
\hline Other Arab countries & $43(4.3)$ & $13.0 \pm 5.1$ & & $22(5 \mid .2)$ & $21(48.8)$ & \\
\hline Australia & $33(3.3)$ & $12.0 \pm 4.5$ & & $15(45.5)$ & $18(54.5)$ & \\
\hline Canada/USA & $16(1.6)$ & $14.7 \pm 4.6$ & & $10(62.5)$ & $6(37.5)$ & \\
\hline Europe & $18(1.8)$ & $12.8 \pm 5.9$ & & $8(44.4)$ & $10(55.6)$ & \\
\hline
\end{tabular}

(Continued) 
Table I (Continued).

\begin{tabular}{|c|c|c|c|c|c|c|}
\hline Variable & All & $\begin{array}{l}\text { Well-Being } \\
\text { Score }\end{array}$ & P-value* & $\begin{array}{l}\text { Good Well-Being } \\
(\geq 12.5)\end{array}$ & $\begin{array}{l}\text { Poor Well-Being } \\
(<12.5)\end{array}$ & P-value* \\
\hline Other & II (I.I) & $13.5 \pm 6.5$ & & $8(72.7)$ & $3(27.3)$ & \\
\hline \multicolumn{7}{|l|}{ Job, n (\%) } \\
\hline Employed for wages & 45 I (45.5) & $13.1 \pm 5.6$ & 0.122 & $24 I(53.4)$ & $210(46.6)$ & 0.718 \\
\hline Self-employed & $45(4.5)$ & $12.9 \pm 6.3$ & & $25(55.6)$ & $20(44.4)$ & \\
\hline Unemployed & $119(12.0)$ & $11.9 \pm 5.8$ & & $56(47.1)$ & $63(52.9)$ & \\
\hline Retired/Cannot work & $19(1.92)$ & $10.4 \pm 6.8$ & & $9(47.4)$ & $10(52.6)$ & \\
\hline Home-maker & $92(9.3)$ & $11.8 \pm 5.6$ & & $43(46.7)$ & $49(53.3)$ & \\
\hline Student & $266(26.8)$ & $12.6 \pm 5.2$ & & 137 (5I.5) & $129(48.5)$ & \\
\hline \multicolumn{7}{|l|}{ Field of work, n (\%) } \\
\hline Medical/Healthcare & $203(20.5)$ & $12.9 \pm 5.5$ & 0.030 & III (54.7) & $92(45.3)$ & 0.065 \\
\hline Education sector & $150(15.1)$ & $12.2 \pm 5.7$ & & $68(45.3)$ & $82(54.7)$ & \\
\hline Academic/Research & $142(14.3)$ & $13.7 \pm 6.0$ & & $86(60.6)$ & $56(39.4)$ & \\
\hline White-collar & $57(5.7)$ & $11.5 \pm 5.5$ & & $26(45.6)$ & $31(54.4)$ & \\
\hline Police/Military & $21(2.1)$ & $14.4 \pm 6.8$ & & $14(66.7)$ & $7(33.3)$ & \\
\hline Blue-collar & $8(0.8)$ & $10.0 \pm 6.4$ & & $3(37.5)$ & $5(62.5)$ & \\
\hline
\end{tabular}

Notes: *Unpaired t-tests or one-way analysis of variance (ANOVA) were applied to compare the mean well-being score with qualitative variables as appropriate. Chi-square and Fisher Exact tests were applied to compare binary variable of well-being with qualitative variables as appropriate. 'Pearson correlation coefficient. The bold value represents the number of participants.

\section{Discussion}

This study explored social media use and its impact on well-being during the COVID-19 pandemic in the UAE, and other Arab-speaking countries. It also explored the use of social media as a mean for seeking knowledge about COVID-19. Over half of participants in our study reported an above-average well-being score, with lower scores found among participants who were non-Emirati and blue-collar workers. Participants who reported using any social media had poorer well-being scores. Being a health care worker and an Emirati showed poorer well-being. Specifically, using Facebook for, extended periods and to to seek COVID-19 information and updates predicted lower well-being scores. In this study, most participants believed in their abilities to validate shared information and shared it as a social responsibility. However, further research should be undertaken to investigate the accuracy of the practice of validating information and the sources used and accessed for validation. According to Figueiras et al, trust in authorities and information sources impacts behaviors and preventive measures during the pandemic. ${ }^{51}$

Although this study cannot indicate a direct and causal relationship between social media use and poorer well-being, these effects should not be ignored. In fact, other studies have investigated anxiety, stress, and depression related to the COVID-19 pandemic in the community and among subgroups. For example, Zhong et al suggested that social media may mediate impact on mental well-being. Also, during the pandemic, social media was described as a sources of information about COVID-19 and a means to share information. ${ }^{27}$

Despite social media being a valuable means of communication, evidence from previous outbreaks suggests a negative impact on people's knowledge, practices, beliefs, and mental health status. Earlier studies have identified social media's role in intensifying anxiety, stress and depression during the Ebola, SARS, ZIKA and MERS outbreaks. 
Table 2 General Media Sources Use and Well-Being Score by Media Use

\begin{tabular}{|c|c|c|c|c|c|c|}
\hline Variable & All & Well-Being Score & P-value* & Good Well-Being $(\geq \mid 2.5)$ & Poor Well-Being $(<\mid 2.5)$ & P-value* \\
\hline \multicolumn{7}{|c|}{ Medium of information on COVID-19 } \\
\hline \multicolumn{7}{|c|}{ Social media } \\
\hline No & $275(27.7)$ & $13.1 \pm 5.5$ & 0.134 & $157(57.1)$ & 118 (42.9) & 0.029 \\
\hline Yes & $717(72.3)$ & $12.5 \pm 5.6$ & & $354(49.4)$ & $363(50.6)$ & \\
\hline \multicolumn{7}{|l|}{ Internet } \\
\hline No & $488(49.2)$ & $12.6 \pm 5.6$ & 0.909 & $253(51.8)$ & $235(48.2)$ & 0.837 \\
\hline Yes & $504(50.8)$ & $12.7 \pm 5.6$ & & $258(5 \mathrm{I} .2)$ & $246(48.8)$ & \\
\hline \multicolumn{7}{|l|}{ TV } \\
\hline No & $570(57.5)$ & $12.5 \pm 5.6$ & 0.593 & $298(52.3)$ & $272(47.7)$ & 0.573 \\
\hline Yes & $422(42.54)$ & $12.7 \pm 5.5$ & & $213(50.5)$ & $209(49.5)$ & \\
\hline \multicolumn{7}{|c|}{ Newspaper } \\
\hline No & $86 \mid(86.8)$ & $12.7 \pm 5.6$ & 0.553 & $448(52.0)$ & $413(48.0)$ & 0.400 \\
\hline Yes & $13 \mid(13.2)$ & $12.3 \pm 5.7$ & & $63(48.1)$ & $68(51.9)$ & \\
\hline \multicolumn{7}{|l|}{ Radio } \\
\hline No & $940(94.8)$ & $12.7 \pm 5.6$ & 0.419 & $485(51.6)$ & $455(48.4)$ & 0.823 \\
\hline Yes & $52(5.2)$ & $12.0 \pm 5.1$ & & $26(50.0)$ & $26(50.0)$ & \\
\hline \multicolumn{7}{|c|}{ Health agencies } \\
\hline No & $958(96.6)$ & $12.6 \pm 5.6$ & 0.280 & $492(51.4)$ & $466(48.6)$ & 0.604 \\
\hline Yes & $34(3.4)$ & $13.6 \pm 5.5$ & & $19(55.9)$ & I5 (44.I) & \\
\hline \multicolumn{7}{|c|}{ Scientific literature } \\
\hline No & $975(98.3)$ & $12.6 \pm 5.6$ & 0.413 & $504(51.7)$ & 47I (48.3) & 0.467 \\
\hline Yes & $17(1.7)$ & $11.5 \pm 6.8$ & & $7(4 I .2)$ & $10(58.8)$ & \\
\hline \multicolumn{7}{|c|}{ Word of mouth } \\
\hline No & 979 (98.7) & $12.6 \pm 5.6$ & 0.373 & $503(5 \mathrm{I} .4)$ & $476(48.6)$ & 0.581 \\
\hline Yes & $13(1.3)$ & $14.0 \pm 5.0$ & & $8(6 \mid .5)$ & $5(38.5)$ & \\
\hline \multicolumn{7}{|c|}{ Hospital/healthcare professional } \\
\hline No & $984(99.2)$ & $12.6 \pm 5.6$ & 0.851 & $507(5 \mathrm{I} .5)$ & $477(48.5)$ & 1.000 \\
\hline Yes & $8(0.8)$ & $13.0 \pm 6.7$ & & $4(50.0)$ & $4(50.0)$ & \\
\hline
\end{tabular}

Notes: *Unpaired tests were applied to compare well-being scores with social media. Chi-square or Fisher Exact tests were applied to compare binary variable of well-being with social media.

A study in South Korea (2020) found that social media use was related to anger and fear. It significantly increased preventive behaviors via risk perceptions and substantially influenced public perceptions of risk issues. Other studies that focused on $\mathrm{H} 1 \mathrm{~N} 1 \mathrm{flu},{ }^{52}$ Avian flu, ${ }^{53}$ and bovine spongiform encephalopathy also suggested similar findings to the South Korean study. ${ }^{54}$ Similarly, a recent study published in China showed that mental health problems, specifically depression 


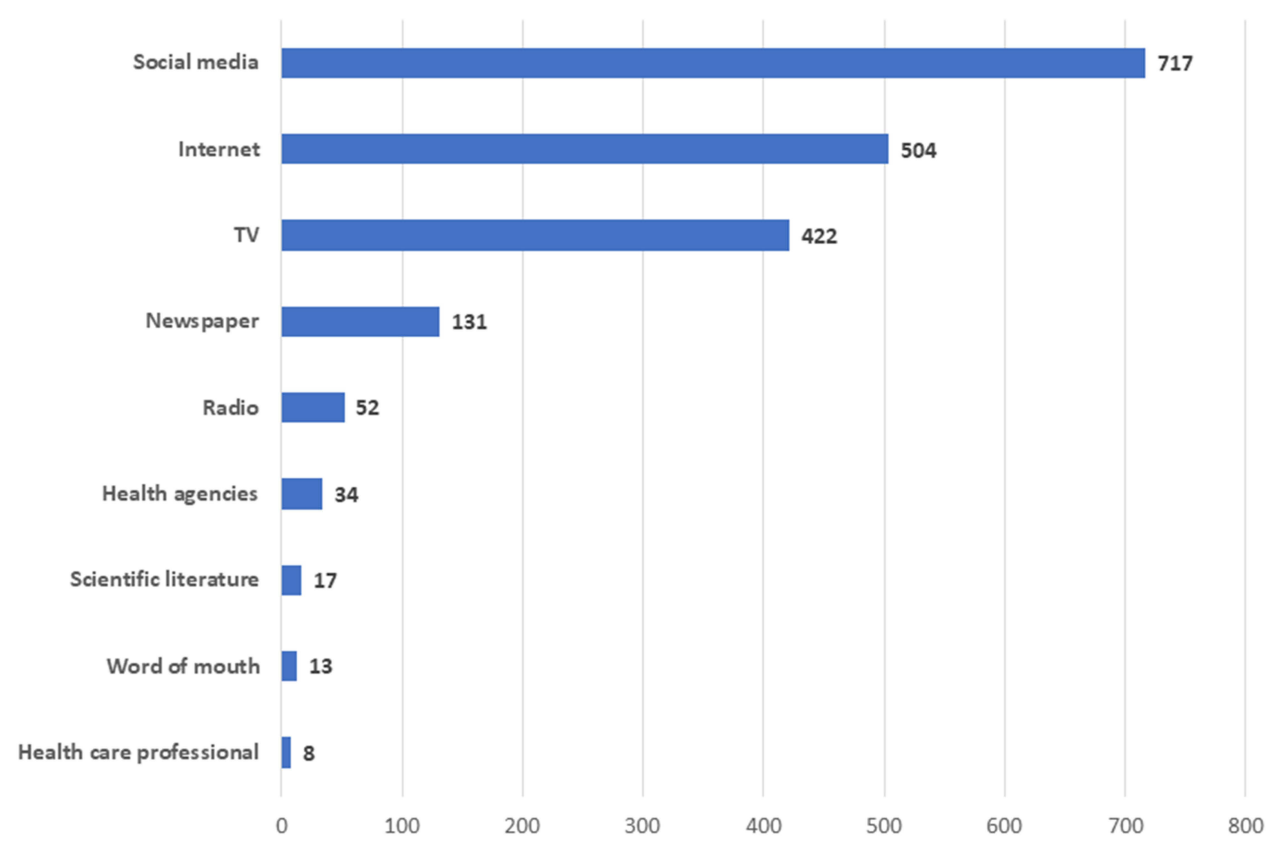

Figure I Medium of information of COVID-19 (N:993).

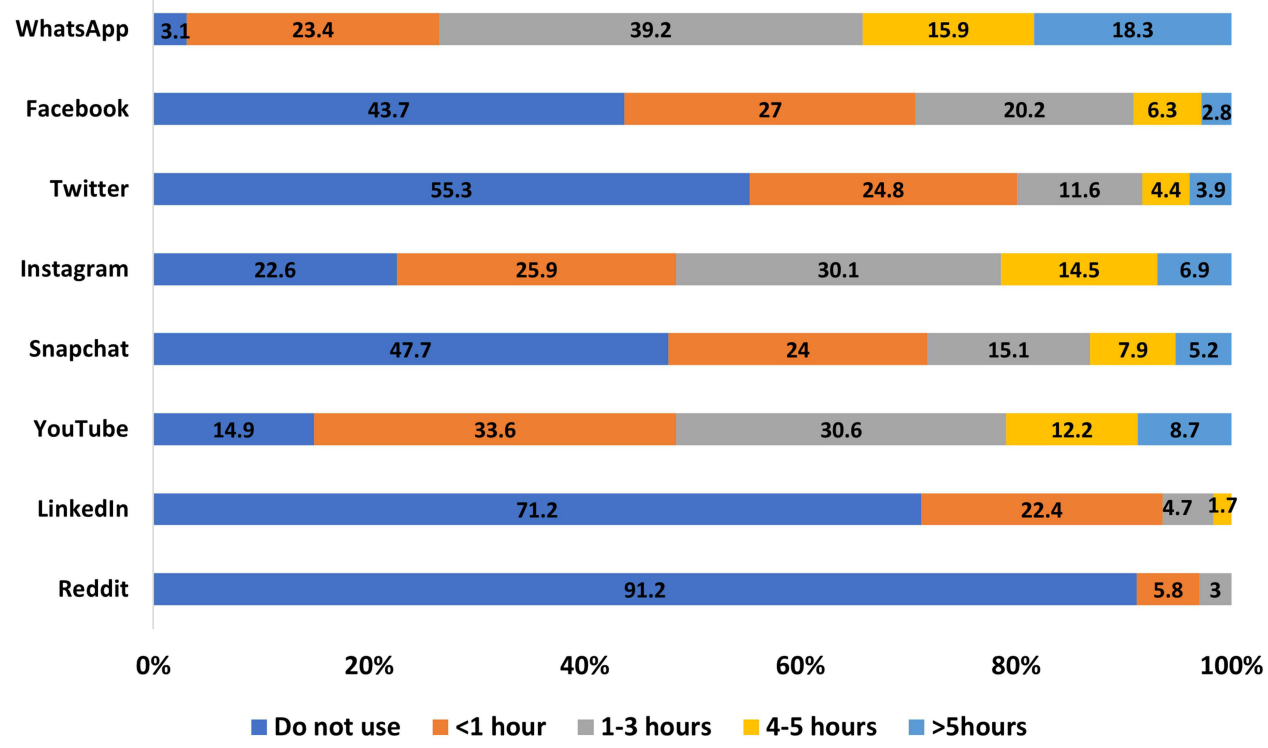

Figure 2 Use of social media (hours per day) (N: 993).

and anxiety, were prevalent and positively associated with social media use during the COVID-19 outbreak, highlighting the significant role of governments in combatting the "infodemic". 55

In this study, being Emirati indicated poorer well-being when associated with social media use. This might be explained by the fact that our sample was mainly Emiratis, or due to the high amount of misinformation that spread at the early stages of the UAE pandemic compared to other neighbouring countries. ${ }^{56}$

Social media platforms are becoming more commonly used to acquire news and information and behavioral change. ${ }^{57}$ This study has shown high use of social media among participants compared to other traditional media platforms such as newspapers, television, and radio programs. However, in this study overuse of certain social media platforms was 
Table 3 Frequency of Social Media Use and Comparison with a Well-Being Score

\begin{tabular}{|c|c|c|c|c|c|c|}
\hline Variable & All & Well-Being Score & P-value* & Good Well-Being $(\geq \mid 2.5)$ & Poor Well-Being $(<12.5)$ & P-value* \\
\hline \multicolumn{7}{|l|}{ Social media } \\
\hline No & $275(27.7)$ & $13.1 \pm 5.5$ & 0.134 & $157(57.1)$ & 118 (42.9) & 0.029 \\
\hline Yes & $717(72.3)$ & $12.5 \pm 5.6$ & & $354(49.4)$ & $363(50.6)$ & \\
\hline \multicolumn{7}{|l|}{ Facebook } \\
\hline Do not use & $406(43.7)$ & $13.4 \pm 5.4$ & $<0.001$ & $243(59.9)$ & $163(40.1)$ & $<0.001$ \\
\hline$<$ l hour & 25 I (27.0) & $12.6 \pm 5.7$ & & $127(50.6)$ & $124(49.4)$ & \\
\hline $1-3$ hours & $188(20.2)$ & $11.3 \pm 5.5$ & & 71 (37.8) & $117(62.2)$ & \\
\hline $3-5$ hours & $59(6.3)$ & $12.5 \pm 5.5$ & & $27(45.8)$ & $32(54.2)$ & \\
\hline$>5$ hours & $26(2.8)$ & $9.5 \pm 6.3$ & & $9(34.6)$ & $17(65.4)$ & \\
\hline \multicolumn{7}{|l|}{ Twitter } \\
\hline Do not use & $498(55.3)$ & $12.4 \pm 5.7$ & 0.224 & $246(49.4)$ & $252(50.6)$ & 0.193 \\
\hline$<$ l hour & $223(24.8)$ & $13.3 \pm 5.2$ & & $130(58.3)$ & $93(41.7)$ & \\
\hline $\mathrm{I}-3$ hours & $104(11.6)$ & $12.4 \pm 5.8$ & & $49(47.1)$ & $55(52.9)$ & \\
\hline $3-5$ hours & $40(4.4)$ & $13.7 \pm 5.1$ & & $22(55.0)$ & $18(45.0)$ & \\
\hline$>5$ hours & 35 (3.9) & $12.6 \pm 5.7$ & & $19(54.3)$ & $16(45.7)$ & \\
\hline \multicolumn{7}{|l|}{ Instagram } \\
\hline Do not use & $211(22.6)$ & $12.4 \pm 5.9$ & 0.130 & $104(49.3)$ & $107(50.7)$ & 0.352 \\
\hline$<1$ hour & $242(25.9)$ & $12.9 \pm 5.7$ & & $129(53.3)$ & II3 (46.7) & \\
\hline $\mathrm{I}-3$ hours & $28 I(30.1)$ & $12.9 \pm 5.6$ & & $147(52.3)$ & $134(47.7)$ & \\
\hline $3-5$ hours & $136(14.5)$ & $13.0 \pm 4.9$ & & $76(55.9)$ & $60(44.1)$ & \\
\hline$>5$ hours & $65(6.9)$ & $|I| \pm 5.4$. & & $27(4 \mid .5)$ & $38(58.5)$ & \\
\hline \multicolumn{7}{|l|}{ YouTube } \\
\hline Do not use & 140 (14.9) & $12.3 \pm 5.7$ & 0.221 & $72(5 \mid .4)$ & $68(48.6)$ & 0.716 \\
\hline$<$ l hour & $316(33.6)$ & $13.1 \pm 5.7$ & & $168(53.2)$ & $148(46.8)$ & \\
\hline I-3 hours & $288(30.6)$ & $12.8 \pm 5.3$ & & I49 (5।.7) & $139(48.3)$ & \\
\hline $3-5$ hours & 115 (12.2) & $12.9 \pm 5.3$ & & $63(54.8)$ & $52(45.2)$ & \\
\hline$>5$ hours & $82(8.7)$ & $11.6 \pm 5.7$ & & $37(45.1)$ & $45(54.9)$ & \\
\hline \multicolumn{7}{|l|}{ Linkedln } \\
\hline Do not use & 638 (7I.2) & $12.6 \pm 5.5$ & 0.345 & $320(50.2)$ & $318(49.8)$ & 0.472 \\
\hline$<$ I hour & $201(22.4)$ & $13.0 \pm 5.5$ & & II I (55.2) & $90(44.8)$ & \\
\hline I-3 hours & $42(4.7)$ & $12.4 \pm 5.9$ & & 24 (57.I) & 18 (42.9) & \\
\hline$>3$ hours & $15(1.7)$ & $14.7 \pm 5.5$ & & $9(60.0)$ & $6(40.0)$ & \\
\hline
\end{tabular}

(Continued) 
Table 3 (Continued).

\begin{tabular}{|l|l|l|l|l|l|l|l|}
\hline Variable & All & Well-Being Score & P-value* & Good Well-Being $(\geq 12.5)$ & Poor Well-Being (<12.5) & P-value* \\
\hline \multicolumn{7}{|l|}{ Reddit } \\
\hline Do not use & $798(91.2)$ & $12.8 \pm 5.6$ & 0.102 & $419(52.5)$ & $379(47.5)$ & 0.287 \\
\hline$<1$ hour & $51(5.8)$ & $11.1 \pm 5.1$ & & $21(41.2)$ & $30(58.8)$ & $13(50.0)$ \\
\hline$\geq 1$ hours & $26(3.0)$ & $13.0 \pm 4.7$ & & $13(50.0)$ & 13 & \\
\hline
\end{tabular}

Notes: *One-way ANOVA tests were applied to compare well-being scores with the frequency of social media use. Chi-square or Fisher Exact tests were applied to compare binary variable of well-being with the frequency of social media use.

negatively associated with well-being; participants who used social media platforms for longer periods of time had lower well-being scores. A similar study showed that social media influenced people's mental health and psychological wellbeing in Iraq, Kurdistan, and its usage was correlated with fear spread and panic. ${ }^{10}$ In the US, the pandemic was linked to a longitudinal decrease in well-being and poorer mood as presented by social media. ${ }^{58}$

In general, over half of the participants scored above average on well-being, highlighting that there might be an equitable effect for social media in accessing information. Our participants indicated strong confidence in their knowledge, practices, and the ability to control the spread of information through WhatsApp and other social media platforms. ${ }^{27}$ This confidence might be because most participants were educated (health care professionals, academics, and students), or that large amounts of information were transmitted before and during the time of data collection for this study and the onset of the pandemic. Zhong et al discussed similar findings that social media affects mental health because younger people rely more on social media to receive information about the pandemic. ${ }^{27}$ It is worth noting that our sample had a considerable number of respondents stating that they are health care workers, which may introduce bias to our results. However, when we controlled our sample by occupation, the differences were not significant. Furthermore, based on recent research, it may be argued that health care professionals have shown higher rates of depression and anxiety during the COVID-19 pandemic, affecting their well-being. ${ }^{59-62}$ Two different studies conducted in the UAE during the COVID-19 pandemic found that health care workers in the UAE suffer from anxiety, psychological distress and burnout. ${ }^{62,63}$ However, our study mainly correlated the well-being of participants with social media practices, not with the type of work. ${ }^{59-61}$

In particular, WhatsApp messaging has been used to help families cope with social isolation and support social inclusion. ${ }^{33}$ WhatsApp was the most common and often used social media platform among participants in our study. Although we did not investigate the reasons for the use of WhatsApp in our research, the everyday use of this platform as a tool for social networking is consistent with other findings. ${ }^{33}$ In the internet-driven information age, there is significant pressure on governmental entities, health officials, and public health specialists to come up with ways to combat the considerable damage of social media on trust in scientific evidence. These effects will likely be felt for more time to come, even after the COVID-19 pandemic wanes. It is becoming increasingly necessary for health and government officials to promote digital literacy as a method to combat the spread of false, misleading, or unreliable information. Several studies reported the role of social media in promoting health protection and highlighted the significance of public health messaging. For example, past research conducted by Collinson et al. showed the value of controlling the dissemination of influenza and decreasing the infection outcomes on a population. ${ }^{14}$ Social media campaigns regarding epidemics or pandemics are in communicating information to the general public, thereby producing positive attitudes and behaviors that may reduce the spread of the disease by means such as handwashing and social distancing. ${ }^{4,17,19,57}$ It is worth pointing out that answering "very often" and "often" to the question of "how often do you look up information" may be an indicator for anxiety and may reflect negatively on well-being. However, in our results, this was not significant and has not shown any impact on well-being.

Various studies have shown a high prevalence of COVID-19 awareness and its impact on practices and attitudes being propagated by the rapid spread of information across the globe through many platforms, including social media. It is 
Table 4 Social Media Practices and Comparison with a Well-Being Score

\begin{tabular}{|c|c|c|c|c|c|c|}
\hline Variable & All & $\begin{array}{l}\text { Well-Being } \\
\text { Score }\end{array}$ & P-value* & $\begin{array}{l}\text { Good Well-Being } \\
(\geq \mid 2.5)\end{array}$ & $\begin{array}{l}\text { Poor Well-Being } \\
(<12.5)\end{array}$ & P-value* \\
\hline \multicolumn{7}{|c|}{ How often do you look up information and updates about COVID-I9? } \\
\hline Not at all & $39(3.9)$ & $13.1 \pm 6.0$ & 0.146 & $22(56.4)$ & $17(43.6)$ & 0.342 \\
\hline Rarely & II $3(11.4)$ & $12.1 \pm 5.4$ & & $60(53.1)$ & $53(46.9)$ & \\
\hline Occasionally & $268(27.0)$ & $12.9 \pm 5.4$ & & $|4|(52.6)$ & $127(47.4)$ & \\
\hline Often & $371(37.4)$ & $12.6 \pm 5.9$ & & $176(47.4)$ & $195(52.6)$ & \\
\hline Very often & $20 \mathrm{I}(20.3)$ & $13.8 \pm 5.2$ & & II $2(55.7)$ & $89(44.3)$ & \\
\hline \multicolumn{7}{|c|}{ Do you follow influencers on social media for COVID-19 information and updates? } \\
\hline Yes & $208(21.0)$ & $12.9 \pm 5.9$ & 0.354 & $110(52.9)$ & $98(47.1)$ & 0.622 \\
\hline No & $654(65.9)$ & $12.4 \pm 5.4$ & & $330(50.5)$ & $324(49.5)$ & \\
\hline I do not know any influencer & $130(13.1)$ & $13.1 \pm 5.8$ & & $71(54.6)$ & $59(45.4)$ & \\
\hline \multicolumn{7}{|c|}{ I only share COVID-I9 related information from official sources or after validating from the official sources? } \\
\hline Strongly Disagree/ Disagree & $39(3.9)$ & $13.6 \pm 7.3$ & 0.021 & $24(61.5)$ & $15(38.5)$ & 0.069 \\
\hline Neither disagree nor agree & $100(10.1)$ & II. $2 \pm 5.6$ & & $42(42.0)$ & $58(58.0)$ & \\
\hline Strongly Agree/ Agree & $853(86.0)$ & $12.8 \pm 5.5$ & & $445(52.2)$ & $408(47.8)$ & \\
\hline \multicolumn{7}{|c|}{ I share COVID-19 related information because: via social media } \\
\hline \multicolumn{7}{|c|}{ It gives me some sense of satisfaction } \\
\hline No & $819(82.6)$ & $12.5 \pm 5.5$ & 0.093 & $410(50.1)$ & $409(49.9)$ & 0.047 \\
\hline Yes & $173(17.5)$ & $13.3 \pm 5.9$ & & I0I (58.4) & $72(41.6)$ & \\
\hline \multicolumn{7}{|l|}{ I want to stay socially interactive } \\
\hline No & $863(87.0)$ & $12.6 \pm 5.6$ & 0.579 & $444(5 I .5)$ & $419(48.5)$ & 0.917 \\
\hline Yes & $129(13.0)$ & $12.9 \pm 5.3$ & & 67 (5I.9) & $62(48.1)$ & \\
\hline \multicolumn{7}{|l|}{ I have no specific reason } \\
\hline No & $859(86.6)$ & $12.8 \pm 5.5$ & 0.018 & $454(52.9)$ & $405(47.1)$ & 0.032 \\
\hline Yes & $133(13.4)$ & $11.6 \pm 6.0$ & & $57(42.9)$ & $76(57.1)$ & \\
\hline \multicolumn{7}{|l|}{ I was asked to forward it } \\
\hline No & $956(69.4)$ & $12.7 \pm 5.6$ & 0.436 & $495(51.8)$ & $46 I(48.2)$ & 0.387 \\
\hline Yes & $36(3.6)$ & $11.9 \pm 4.9$ & & $16(44.4)$ & $20(55.6)$ & \\
\hline \multicolumn{7}{|c|}{ I feel responsible to share knowledge } \\
\hline No & $377(38.0)$ & $12.3 \pm 6.1$ & 0.201 & $192(50.9)$ & $185(49.1)$ & 0.773 \\
\hline Yes & $615(62.0)$ & $12.8 \pm 5.3$ & & $319(51.9)$ & $296(48.1)$ & \\
\hline \multicolumn{7}{|l|}{ I wish to stay informed } \\
\hline No & $948(95.6)$ & $12.6 \pm 5.6$ & 0.607 & $49 \mid(5 I .8)$ & $457(48.2)$ & $0.41 \mathrm{I}$ \\
\hline
\end{tabular}


Table 4 (Continued).

\begin{tabular}{|c|c|c|c|c|c|c|}
\hline Variable & All & $\begin{array}{l}\text { Well-Being } \\
\text { Score }\end{array}$ & P-value* & $\begin{array}{l}\text { Good Well-Being } \\
(\geq 12.5)\end{array}$ & $\begin{array}{l}\text { Poor Well-Being } \\
(<12.5)\end{array}$ & P-value* \\
\hline Yes & $44(4.4)$ & $12.2 \pm 5.6$ & & $20(45.5)$ & $24(54.5)$ & \\
\hline \multicolumn{7}{|c|}{ I am confident in my ability to differentiate between true and false information related to COVID-I9? } \\
\hline Strongly disagree/Disagree & $38(3.8)$ & $\mid 4.1 \pm 5.5$ & $\leq 0.001$ & $24(63.2)$ & $14(36.8)$ & $\leq 0.001$ \\
\hline Neither disagree nor agree & $180(18.1)$ & II.I \pm 5.3 & & $64(35.6)$ & $116(64.4)$ & \\
\hline Strongly agree/ Agree & $774(78.0)$ & $13.0 \pm 5.6$ & & $423(54.7)$ & $35 I(45.3)$ & \\
\hline \multicolumn{7}{|c|}{ When I receive dubious or false COVID-I9 related information, I inform the sender or try to correct them } \\
\hline \multirow[t]{2}{*}{ Strongly disagree/ Disagree } & $23(2.3)$ & $9.7 \pm 4.8$ & 0.011 & $7(30.4)$ & $16(69.6)$ & 0.027 \\
\hline & $73(7.4)$ & $12.4 \pm 5.6$ & & $32(43.8)$ & $41(56.2)$ & \\
\hline Neither disagree nor agree & $25 I(25.3)$ & $12.1 \pm 5.5$ & & $120(47.8)$ & $13 \mid(52.2)$ & \\
\hline \multirow[t]{2}{*}{ Strongly agree /Agree } & $349(35.2)$ & $12.7 \pm 5.3$ & & $183(52.4)$ & $166(47.6)$ & \\
\hline & $296(29.8)$ & $13.3 \pm 5.9$ & & $169(57.1)$ & $127(42.9)$ & \\
\hline \multicolumn{7}{|c|}{ My knowledge and awareness of health-related issues has increased as a result of the COVID-19 pandemic } \\
\hline Strongly disagree/Disagree & $4 I(4.1)$ & $13.0 \pm 5.9$ & 0.046 & $23(56.1)$ & $18(43.9)$ & 0.003 \\
\hline Neither disagree nor agree & $169(17.0)$ & $1 \mathrm{I} .7 \pm 5.7$ & & $67(39.6)$ & $102(60.4)$ & \\
\hline Strongly agree/ agree & 782 (78.8.) & $12.8 \pm 5.5$ & & 421 (53.8) & $36 I(46.2)$ & \\
\hline
\end{tabular}

Notes: *Unpaired t-tests or one-way ANOVA tests were applied to compare well-being score with the frequency of social media use. Chi-square or Fisher Exact tests were applied to compare binary variable of well-being with the frequency of social media use.

worth noting that during the COVID-19 pandemic, both the virus and the information/misinformation around the outbreak spread very fast. ${ }^{3,5,18}$ This awareness could provide valuable context to the levels of confidence that participants of this study expressed they had in their knowledge and their indication that they only shared correct information and confirmed the truthfulness of information before disseminating it further. It can be argued that factors that may have led to amplified use of social media during this pandemic can be linked to the pandemic, its subsequent social isolation, and stringent containment measures that led to marked restrictions in typical social communication, unlike any of the previous historical epidemics and pandemics. ${ }^{64}$

Throughout pandemics, the primary research on social media was during the 2009 H1N1 outbreak, tracing the prevalence of misinformation (reported as 4.5\%), terminology use (H1N1 or swine flu), public attitudes and fear, and relationships between case incidence and public concern. ${ }^{65}$ Furthermore, some individuals generate assumptions regarding disease transmission, often based on incorrect risk perceptions and pre-existing social prejudices, to ease the anxiety felt by the accusers or stigmatize those who are blamed. This was reported in April 2009 when a new strain of human influenza H1N1 emerged in Mexico and spread quickly worldwide. ${ }^{66}$ This resulted in an economic crisis that affected Mexican goods as they were considered disease vectors. ${ }^{67}$ To decrease the adverse outcomes of stigmatization during pandemics, public health officials must attempt to identify the dynamics that underlie this process, with particular attention given to protecting disadvantaged people. ${ }^{10,21,57,68,69}$

Moreover, a past study investigating media dependency amongst Chinese nationals during the SARS epidemic of 2003 found that the internet was a unique empowerment tool that allowed people to avoid official authority and challenge official claims during the crisis. ${ }^{31}$ In 2015, Misra et al. developed a model to explore the impact of awareness realized by social media campaigns on infectious disease prevalence. The study findings revealed that social media health campaigns 
Table 5 Crude and Adjusted Linear Regression Analysis of Well-Being Score with Social Media Use and Practices

\begin{tabular}{|c|c|c|c|c|}
\hline Variable & $\begin{array}{l}\text { Unadjusted Estimate } \\
(95 \% \mathrm{Cl})\end{array}$ & P-value* & $\begin{array}{l}\text { Adjusted Estimate } \\
(95 \% \mathrm{Cl})\end{array}$ & P-value* \\
\hline \multicolumn{5}{|l|}{ Facebook } \\
\hline$<1$ hourl & $-0.78(-1.65-0.09)$ & 0.078 & $-0.19(-1.30-0.92)$ & 0.734 \\
\hline I-3 hours/ & $-2.09(-3.04--1.13)$ & $<0.001$ & $-1.53(-2.79--0.27)$ & 0.017 \\
\hline 3-5 hours/ Do not use & $-0.95(-2.45-0.56)$ & 0.216 & $-0.04(-2.00-1.91)$ & 0.965 \\
\hline$>5$ hours/ Do not use & $-3.87(-6.05--1.68)$ & 0.001 & $-0.317(-5.78--0.55)$ & 0.018 \\
\hline$R^{2}$ & 0.028 & & 0.054 & \\
\hline \multicolumn{5}{|l|}{ Twitter } \\
\hline$<$ I hour/ Do not use & $0.92(0.05-1.80)$ & 0.039 & $0.85(-0.17-1.87)$ & 0.101 \\
\hline I-3 hours/ Do not use & $0.01(-1.17-1.18)$ & 0.998 & $-0.38(-1.67-0.92)$ & 0.569 \\
\hline 3-5 hours/ Do not use & $1.23(-0.56-3.02)$ & 0.179 & $0.74(-|.23-2.7|)$ & 0.461 \\
\hline$>5$ hours/ Do not use & $2.07(-1.70-2.11)$ & 0.831 & $-0.52(-2.67-1.63)$ & 0.633 \\
\hline$R^{2}$ & 0.006 & & 0.046 & \\
\hline \multicolumn{5}{|l|}{ Instagram } \\
\hline$<$ I hour/ Do not use & $0.46(-0.57-1.49)$ & 0.381 & $1.08(-0.10-2.26)$ & 0.072 \\
\hline I-3 hours/ Do not use & $0.48(-0.5 \mathrm{I}-\mathrm{I} .49)$ & 0.339 & $0.54(-0.67-1.76)$ & 0.379 \\
\hline 3-5 hours/ Do not use & $0.62(-0.58-1.82)$ & 0.313 & $0.13(-1.37-1.64)$ & 0.860 \\
\hline$>5$ hours/ Do not use & $-1.33(-2.88-0.21)$ & 0.091 & $-1.09(-2.92-0.73)$ & $0.24 I$ \\
\hline$R^{2}$ & 0.008 & & 0.048 & \\
\hline \multicolumn{5}{|l|}{ You ITube } \\
\hline$<$ I hour/ Do not use & $0.76(-0.35-1.87)$ & 0.178 & $0.27(-1.03-1.58)$ & 0.683 \\
\hline I-3 hours/ Do not use & $0.45(-0.67-1.57)$ & 0.433 & $-0.22(-1.57-1.13)$ & 0.748 \\
\hline 3-5 hours/ Do not use & $0.58(-0.80-1.95)$ & $0.41 \mathrm{I}$ & $-0.27(-1.89-1.34)$ & 0.738 \\
\hline$>5$ hours/ Do not use & $-0.75(-2.27-0.76)$ & 0.329 & $-0.98(-2.78-0.82)$ & 0.285 \\
\hline$R^{2}$ & 0.006 & & 0.040 & \\
\hline \multicolumn{5}{|l|}{ Linkedln } \\
\hline$<$ I hour/ Do not use & $0.48(-0.40-1.36)$ & 0.285 & $0.99(-0.11-2.09)$ & 0.078 \\
\hline I-3 hours/ Do not use & $-0.18(-1.91-1.55)$ & 0.838 & $0.55(-1.58-2.69)$ & 0.610 \\
\hline$>3$ hours/ Do not use & $2.17(-0.67-5.01)$ & 0.133 & $2.40(-1.08-5.88)$ & 0.177 \\
\hline$R^{2}$ & 0.004 & & 0.047 & \\
\hline \multicolumn{5}{|l|}{ Reddit } \\
\hline$<1$ hour/ Do not use & $-1.70(-3.26--0.13)$ & 0.034 & $-2.24(-3.98--0.51)$ & 0.011 \\
\hline$\geq 1$ hours/ Do not use & $0.19(-1.98-2.35)$ & 0.865 & $1.42(-1.50-4.34)$ & 0.341 \\
\hline $\mathrm{R}^{2}$ & 0.005 & & 0.050 & \\
\hline
\end{tabular}


Table 5 (Continued).

\begin{tabular}{|c|c|c|c|c|}
\hline Variable & $\begin{array}{l}\text { Unadjusted Estimate } \\
(95 \% \mathrm{Cl})\end{array}$ & P-value* & $\begin{array}{l}\text { Adjusted Estimate } \\
(95 \% \mathrm{Cl})\end{array}$ & P-value* \\
\hline \multicolumn{5}{|c|}{ How often do you look up information and updates about COVID-19? } \\
\hline Rarely/ Not at all & $-1.29(-3.22-0.74)$ & 0.214 & $-2.13(-4.36-1.00)$ & 0.060 \\
\hline Occasionally/ Not at all & $-0.98(-2.85-0.90)$ & 0.307 & $-2.08(4.16--0.01)$ & 0.050 \\
\hline Often/ Not at all & $-1.74(-3.58-0.11)$ & 0.065 & $-2.99(-5.03--0.95)$ & 0.004 \\
\hline Very often/ Not at all & $-0.78(-2.69-1.14)$ & 0.427 & $-1.91(-4.04-0.23)$ & 0.080 \\
\hline$R^{2}$ & 0.007 & & 0.055 & \\
\hline \multicolumn{5}{|c|}{ Do you follow influencers on social media for COVID-19 information and updates? } \\
\hline Yes/ No & $0.47(-0.40-1.34)$ & 0.291 & $0.21(-0.77--1.19)$ & 0.680 \\
\hline I do not know any influencer/ No & $0.63(-0.42-1.68)$ & $0.24 I$ & $0.20(-1.01-1.40)$ & 0.749 \\
\hline$R^{2}$ & 0.002 & & 0.041 & \\
\hline \multicolumn{5}{|c|}{ I only share COVID-19 related information from official sources or after validating from the official sources? } \\
\hline Disagree/ Neither disagree nor agree & $2.24(-0.29-4.77)$ & 0.083 & $1.34(-1.54-4.22)$ & 0.362 \\
\hline Strongly disagree/ Neither disagree nor agree & $2.51(-0.43-5.45)$ & 0.094 & $3.78(0.36-7.20)$ & 0.030 \\
\hline Agree/ Neither disagree nor agree & $0.99(-0.3 \mathrm{I}-2.30)$ & 0.137 & $0.67(-0.85-2.19)$ & 0.389 \\
\hline Strongly agree/ Neither disagree nor agree & $1.70(0.52-2.88)$ & 0.005 & I.II (-0.29-2.50) & 0.121 \\
\hline$R^{2}$ & 0.011 & & 0.048 & \\
\hline \multicolumn{5}{|l|}{ I share COVID-I 9 related information because: } \\
\hline It gives me some sense of satisfaction (Yes/No) & $0.79(-0.13-1.70)$ & 0.093 & $0.83(-0.20-1.85)$ & 0.115 \\
\hline$R^{2}$ & 0.003 & & 0.044 & \\
\hline I want to stay socially interactive (Yes/No) & $0.29(-0.74-1.33)$ & 0.579 & $-0.21(-1.38-0.96)$ & 0.720 \\
\hline$R^{2}$ & 0.001 & & 0.041 & \\
\hline I have no specific reason (Yes/No) & $-1.23(-2.24--0.21)$ & 0.018 & $-0.89(-2.05-0.27)$ & 0.131 \\
\hline $\mathrm{R}^{2}$ & 0.006 & & 0.044 & \\
\hline I was asked to forward it (Yes/No) & $-0.74(-2.60-1.12)$ & 0.436 & $-2.05(-4.19-0.09)$ & 0.060 \\
\hline$R^{2}$ & 0.001 & & 0.045 & \\
\hline I feel responsible to share knowledge (Yes/No) & $0.47(-0.25-1.18)$ & 0.202 & $0.19(-0.62-1.01)$ & 0.646 \\
\hline$R^{2}$ & 0.002 & & 0.041 & \\
\hline I wish to stay informed (Yes/No) & $-0.44(-2.13-1.25)$ & 0.606 & $-0.82(-2.58-0.95)$ & 0.364 \\
\hline $\mathrm{R}^{2}$ & 0.001 & & 0.042 & \\
\hline \multicolumn{5}{|c|}{ I am confident in my ability to differentiate between true and false information related to COVID-I9? } \\
\hline Disagree or Strongly disagree/ Neither disagree nor agree & $3.02(1.08-4.96)$ & $<0.001$ & $2.81(0.49-5.13)$ & 0.018 \\
\hline Agree/ Neither disagree nor agree & $1.52(0.56-2.48)$ & 0.002 & $1.61(0.52-2.70)$ & 0.004 \\
\hline
\end{tabular}

(Continued) 
Table 5 (Continued).

\begin{tabular}{|c|c|c|c|c|}
\hline Variable & $\begin{array}{l}\text { Unadjusted Estimate } \\
(95 \% \mathrm{Cl})\end{array}$ & P-value* & $\begin{array}{l}\text { Adjusted Estimate } \\
(95 \% \mathrm{Cl})\end{array}$ & P-value* \\
\hline Strongly agree/ Neither disagree nor agree & $2.31(1.30-3.31)$ & 0.002 & $1.70(0.56-2.83)$ & 0.003 \\
\hline $\mathrm{R}^{2}$ & 0.023 & & 0.056 & \\
\hline \multicolumn{5}{|c|}{ When I receive dubious or false COVID-I9 related information, I inform the sender or try to correct them } \\
\hline Disagree/ Neither disagree nor agree & $0.32(-1.13-1.77)$ & 0.662 & $-0.92(-2.55-0.7 I)$ & 0.267 \\
\hline Strongly disagree/ Neither disagree nor agree & $-2.43(-4.8 I--0.06)$ & 0.045 & $-2.50(-5.13-0.13)$ & 0.063 \\
\hline Agree/ Neither disagree nor agree & $0.63(0.27-1.53)$ & 0.172 & $0.35(-0.69-1.38)$ & 0.509 \\
\hline Strongly agree/ Neither disagree nor agree & $1.18(0.25-2.12)$ & 0.013 & $0.57(-0.5 \mathrm{I}-\mathrm{I} .64)$ & 0.301 \\
\hline $\mathrm{R}^{2}$ & 0.013 & & 0.051 & \\
\hline \multicolumn{5}{|c|}{ My knowledge and awareness of health-related issues has increased as a result of the COVID-19 pandemic } \\
\hline Disagree or Strongly disagree/ Neither disagree nor agree & $1.33(-0.57-3.23)$ & 0.170 & $0.98(-1.29-3.25)$ & 0.396 \\
\hline Agree/ Neither disagree nor agree & $0.91(-0.07-1.90)$ & 0.068 & $0.49(-0.6 I-1.60)$ & 0.380 \\
\hline Strongly agree/ Neither disagree nor agree & $1.50(0.45-2.53)$ & 0.005 & $0.69(-0.47-1.86)$ & 0.244 \\
\hline $\mathrm{R}^{2}$ & 0.008 & & 0.043 & \\
\hline
\end{tabular}

Note: The multiple linear regression model was adjusted for age, sex, education, marital status, nationality, and job.

lead to behavioral changes among individuals, causing them to isolate themselves and protect themselves from infection, thereby decreasing the number of infected people. ${ }^{32}$

In the earlier stages of the pandemic (during the survey distribution period), misinformation and disinformation spread was at its peak. Interventions by leading authorities around the globe and international organizations started to appear as the infodemic effect started, especially with vaccine uptake and testing and preventive measures. The UAE's efforts to contain the pandemic and spread awareness were especially impressive, placing it at the top of the list of countries with effective mass-testing and spread awareness was especially remarkable, with effective mass-testing and vaccine coverage. ${ }^{70}$ Globally, governments and corporations have used various means to try and stem the tide of misinformation. Recently, YouTube and Twitter tried to introduce terms and policies regarding content deemed to be COVID-19 and vaccination misinformation. Programs and calls for e-literacy and digital health education are already in place to combat the social media-caused negative impact on knowledge and awareness, which we hope will decrease the negative effect on well-being. ${ }^{69}$

We acknowledge that there are limitations to this study, including the cross-sectional design and online nature of the survey, which may lead to bias. Moreover, other confounding factors may affect well-being scores such as self-esteem, family relations, physical health, and other factors not considered in this study. Additionally, not having a control group of non-social media users for comparison of baseline well-being scores is a limitation to this study and future studies should consider this. As the survey was online, there is potential for more educated, younger, and affluent people with internet access to respond. However, given the nature of the pandemic and the limitations associated with conducting research using more robust methods, the results are helpful for providing baseline data to inform further research investigating the impact of social media on well-being in the future.

\section{Conclusion}

This study confirms the importance of authority intervention and guidelines that may be needed to control facets of social media use and reduce the negative impacts on health and well-being. Awareness campaigns and collaborative efforts 
between public health authorities and specialists and information technology and communication specialists, are needed. Further studies on the impact of social media during pandemics are needed too to ensure responsible and constructive use of social media. Providing factual, evidence-based information and making them accessible to consumers is highly important to reduce negative impact on the well-being. Public health communities need to learn how to engage the public to make healthy choices while raising public awareness.

\section{Ethics Approval and Informed Consent}

The study was approved by the Ethics Committees of the Abu Dhabi University (on May 16, 2020) (CHS-20-0500014) and was in complete agreement with the Declaration of Helsinki. All participants received information about the study via weblink before starting the questionnaire. Only those who agreed to participate were able to complete the survey.

\section{Acknowledgments}

The authors would like to thank all participants and all of those who shared the questionnaire through their social media platforms.

\section{Author Contributions}

IE conceived the idea and prepared the study design, questionnaire, acquisition of the data, drafting the paper and critically reviewing the article. BS, MG, EB, ES and DEL reviewed the questionnaire. FA analysed the data and presented the tables. All authors made a significant contribution to the work reported, whether that is in the conception, study design, execution, acquisition of data, analysis and interpretation, or in all these areas; took part in drafting, revising or critically reviewing the article; gave final approval of the version to be published; have agreed on the journal to which the article has been submitted; and agree to be accountable for all aspects of the work.

\section{Funding}

No funding was provided to this study.

\section{Disclosure}

The authors report no conflicts of interest in this work.

\section{References}

1. Mao R, Liang J, Shen J, et al. Implications of COVID-19 for patients with pre-existing digestive diseases. Lancet Gastroenterol Hepatol. 2020;5 (5):425-427. doi:10.1016/s2468-1253(20)30076-5

2. Centre for Disease control and Prevention (CDC). Public health response to the initiation and spread of pandemic COVID-19 in the United States, February 24-April 21, 2020. Available from: https://www.cdc.gov/mmwr/volumes/69/wr/mm6918e2.htm. Accessed January $24,2022$.

3. Alwan NA, Burgess RA, Ashworth S, et al. Scientific consensus on the COVID-19 pandemic: we need to act now. Lancet. 2020;396(10260):e71e72. doi:10.1016/S0140-6736(20)32153-X

4. Al-Dmour H, Masa'deh R, Salman A, Abuhashesh M, Al-Dmour R. Influence of social media platforms on public health protection against the COVID-19 pandemic via the mediating effects of public health awareness and behavioral changes: integrated model. J Med Internet Res. 2020;22 (8):e19996. doi:10.2196/19996

5. World Health Organization. Managing the covid-19 infodemic: promoting healthy behaviors and mitigating the harm from misinformation and disinformation. Available from: https://www.who.int/news/item/23-09-2020-managing-the-covid-19-infodemic-promoting-healthy-behaviours-andmitigating-the-harm-from-misinformation-and-disinformation. Accessed January 24, 2022.

6. Carr CT, Hayes RA. Social media: defining, developing, and divining. Atl J Commun. 2015;23(1):46-65. doi:10.1080/15456870.2015.972282

7. McGowan BS, Wasko M, Vartabedian BS, Miller RS, Freiherr DD, Abdolrasulnia M. Understanding the factors that influence the adoption and meaningful use of social media by physicians to share medical information. J Med Internet Res. 2012;14(5):e117. doi:10.2196/jmir.2138

8. Li L, Zhang Q, Wang X, et al. Characterizing the propagation of situational information in social media during COVID-19 epidemic: a case study on Weibo. IEEE Trans Comput Soc Syst. 2020;7(2):556-562. doi:10.1109/TCSS.2020.2980007

9. Su Z, McDonnell D, Wen J, et al. Mental health consequences of COVID-19 media coverage: the need for effective crisis communication practices. Global Health. 2021;17(1):4. doi:10.1186/s12992-020-00654-4

10. Ahmad AR, Murad HR. The impact of social media on panic during the COVID-19 pandemic in Iraqi Kurdistan: online questionnaire study. $J$ Med Internet Res. 2020;22(5):e19556. doi:10.2196/19556

11. Arora T, Grey I, Östlundh L, Lam KBH, Omar OM, Arnone D. The prevalence of psychological consequences of COVID-19: a systematic review and meta-analysis of observational studies. J Health Psychol. 2020;1359105320966639. doi:10.1177/1359105320966639 
12. Brooks SK, Smith LE, Woodland L, et al. The psychological impact of quarantine and how to reduce it: rapid review of the evidence. Lancet. 2020;395(10227):912-920. doi:10.1016/S0140-6736(20)30460-8

13. Cauberghe V, Van Wesenbeeck I, De Jans S, Hudders L, Ponnet K. How adolescents use social media to cope with feelings of loneliness and anxiety during COVID-19 lockdown. Cyberpsychol Behav Soc Netw. 2020;24(4):250-257. doi:10.1089/cyber.2020.0478

14. Collinson S, Khan K, Heffernan JM. The effects of media reports on disease spread and important public health measurements. PLoS One. 2015;10 (11):e0141423. doi:10.1371/journal.pone.0141423

15. Sarah Vieweg ALH, Starbird K, Palen L. Microblogging during two natural hazards events: what twitter may contribute to situational awareness; 2010:1079-1088.

16. Weinstein E. The social media see-saw: positive and negative influences on adolescents' affective well-being. New Media Soc. 2018;20 (10):3597-3623. doi:10.1177/1461444818755634

17. Mavragani A. Infodemiology and infoveillance: scoping review. J Med Internet Res. 2020;22(4):e16206. doi:10.2196/16206

18. Swire-Thompson B, Lazer D. Public health and online misinformation: challenges and recommendations. Annu Rev Public Health. 2020;41 (1):433-451. doi:10.1146/annurev-publhealth-040119-094127

19. Hernández-García I, Giménez-Júlvez T. Assessment of health information about COVID-19 prevention on the internet: infodemiological study. JMIR Public Health Surveill. 2020;6(2):e18717. doi:10.2196/18717

20. Li X, Liu Q. Social media use, eHealth literacy, disease knowledge, and preventive behaviors in the COVID-19 pandemic: cross-sectional study on Chinese Netizens. J Med Internet Res. 2020;22(10):e19684. doi:10.2196/19684

21. Harris M. Coronavirus fears have inspired shaming and death threats online. This is how public concern turns into harassment. The insider; 2020.

22. Woo H, Cho Y, Shim E, Lee JK, Lee CG, Kim SH. Estimating influenza outbreaks using both search engine query data and social media data in South Korea. J Med Internet Res. 2016;18(7):e177. doi:10.2196/jmir.4955

23. Eysenbach G. Infodemiology and infoveillance: framework for an emerging set of public health informatics methods to analyze search, communication and publication behavior on the Internet. J Med Internet Res. 2009;11(1):e11. doi:10.2196/jmir.1157

24. Abi-Jaoude E, Naylor KT, Pignatiello A. Smartphones, social media use and youth mental health. CMAJ. 2020;192(6):E136-E141. doi:10.1503/ cmaj.190434

25. Karim F, Oyewande AA, Abdalla LF, Chaudhry Ehsanullah R, Khan S. Social media use and its connection to mental health: a systematic review. Cureus. 2020;12(6):e8627. doi:10.7759/cureus.8627

26. Escobar Echavarría J, Montoya González LE, Restrepo Bernal D, Mejía Rodríguez D. Cyberbullying and suicidal behavior: what is the connection? About a case]. Rev Colomb Psiquiatr. 2017;46(4):247-251. doi:10.1016/j.rcp.2016.08.004

27. Zhong B, Jiang Z, Xie W, Qin X. Association of social media use with mental health conditions of nonpatients during the COVID-19 outbreak: insights from a national survey study. J Med Internet Res. 2020;22(12):e23696. doi:10.2196/23696

28. Alradhawi M, Shubber N, Sheppard J, Ali Y. Effects of the COVID-19 pandemic on mental well-being amongst individuals in society- A letter to the editor on "The socio-economic implications of the coronavirus and COVID-19 pandemic: a review". Int J Surg. 2020;78:147-148. doi:10.1016/ j.ijsu.2020.04.070

29. Burnap P, Williams ML, Sloan L, et al. Tweeting the terror: modelling the social media reaction to the Woolwich terrorist attack. Soc Netw Anal Min. 2014;4(1):206. doi:10.1007/s13278-014-0206-4

30. McCauley M, Minsky S, Viswanath K. The H1N1 pandemic: media frames, stigmatization and coping. BMC Public Health. $2013 ; 13(1): 1116$. doi:10.1186/1471-2458-13-1116

31. Tai Z, Sun T. Media dependencies in a changing media environment: the case of the 2003 SARS epidemic in China. New Media Soc. 2007;9 (6): $987-1009$. doi:10.1177/1461444807082691

32. Misra AK, Sharma A, Shukla JB. Stability analysis and optimal control of an epidemic model with awareness programs by media. Biosystems. 2015;138:53-62. doi:10.1016/j.biosystems.2015.11.002

33. Stip E, Mugaddam FA, Amiri L. Facing confinement, the comfort of whatsapp groups in mental health communities. Can J Psychiatry. 2020:706743720949341. doi:10.1177/0706743720949341

34. Mejova Y, Kalimeri K. COVID-19 on Facebook Ads: competing agenda around a public health crisis; June, 2020:22-31.

35. Radwan E, Radwan A, Radwan W. The role of social media in spreading panic among primary and secondary school students during the COVID-19 pandemic: an online questionnaire study from the Gaza Strip, Palestine. Heliyon. 2020;6(12):e05807. doi:10.1016/j.heliyon.2020. e05807

36. Beyens I, Pouwels JL, van Driel II, Keijsers L, Valkenburg PM. The effect of social media on well-being differs from adolescent to adolescent. Sci Rep. 2020;10(1):10763. doi:10.1038/s41598-020-67727-7

37. Depoux A, Martin S, Karafillakis E, Preet R, Wilder-Smith A, Larson H. The pandemic of social media panic travels faster than the COVID-19 outbreak. J Travel Med. 2020;27(3). doi:10.1093/jtm/taaa031

38. Ostic D, Qalati SA, Barbosa B, et al. Effects of social media use on psychological well-being: a mediated model. Front Psychol. $2021 ; 12: 2381$. doi:10.3389/fpsyg.2021.678766

39. Apuke OD, Omar B. Modelling the antecedent factors that affect online fake news sharing on COVID-19: the moderating role of fake news knowledge. Health Educ Res. 2020;35(5):490-503. doi:10.1093/her/cyaa030

40. Pennycook G, McPhetres J, Zhang Y, Lu JG, Rand DG. Fighting COVID-19 misinformation on social media: experimental evidence for a scalable accuracy-nudge intervention. Psychol Sci. 2020;31(7):770-780. doi:10.1177/0956797620939054

41. Wongkoblap A, Vadillo MA, Curcin V. Researching mental health disorders in the era of social media: systematic review. J Med Internet Res. 2017;19(6):e228. doi:10.2196/jmir.7215

42. Gao J, Zheng P, Jia Y, et al. Mental health problems and social media exposure during COVID-19 outbreak. PLoS One. $2020 ; 15(4)$ :e0231924. doi:10.1371/journal.pone.0231924

43. Sibai AM, Chaaya M, Tohme RA, Mahfoud Z, Al-Amin H. Validation of the Arabic version of the 5-item WHO well being index in elderly population. Int J Geriatr Psychiatry. 2009;24(1):106-107. doi:10.1002/gps.2079

44. World Health Organization. Wellbeing measures in primary health care/The Depcare Project; 1998. Available from: https://www.euro.who.int/ data/assets/pdf_file/0016/130750/E60246.pdf. Accessed January 24, 2022. 
45. Eysenbach G. Improving the quality of Web surveys: the Checklist for Reporting Results of Internet E-Surveys (CHERRIES). J Med Internet Res. 2004;6(3):e34. doi:10.2196/jmir.6.3.e34

46. Survey Monkey Inc [homepage]. Available at:https://www.surveymonkey.com/. Accessed June 24, 2020.

47. UN High Commissioner for Refugees (UNHCR). Assessing mental health and psychosocial needs and resources - Toolkit for humanitarian settings; 2012. Available from: https://www.refworld.org/docid/55b889c34.html. Accessed January 23, 2021.

48. Child Outcomes Research Consortium (CORC). The World health Organization Five Well-Being Index (WHO-5). Available from: https://www. corc.uk.net/outcome-experience-measures/the-world-health-organisation-five-well-being-index-who-5/. Accessed JFebruary 02, 2020.

49. Topp CW, Østergaard SD, Søndergaard S, Bech P. The WHO-5 well-being index: a systematic review of the literature. Psychother Psychosom. 2015;84(3):167-176. doi:10.1159/000376585

50. Schønning V, Hjetland GJ, Aarø LE, Skogen JC. Social media use and mental health and well-being among adolescents - a scoping review. Front Psychol. 2020;11:1949. doi:10.3389/fpsyg.2020.01949

51. Figueiras MJ, Ghorayeb J, Coutinho MVC, Marôco J, Thomas J. Levels of trust in information sources as a predictor of protective health behaviors during COVID-19 pandemic: a UAE cross-sectional study. Front Psychol. 2021;12:2780. doi:10.3389/fpsyg.2021.633550

52. Jung Oh H, Hove T, Paek H-J, Lee B, Lee H, Kyu Song S. Attention cycles and the H1N1 pandemic: a cross-national study of US and Korean newspaper coverage. Asian J Commun. 2012;22(2):214-232. doi:10.1080/01292986.2011.642395

53. Fung TK, Namkoong K, Brossard D. Media, social proximity, and risk: a comparative analysis of newspaper coverage of Avian Flu in Hong Kong and in the United States. J Health Commun. 2011;16(8):889-907. doi:10.1080/10810730.2011.561913

54. Paek HJ, Oh SH, Hove T. How fear-arousing news messages affect risk perceptions and intention to talk about risk. Health Commun. 2016;31 (9):1051-1062. doi:10.1080/10410236.2015.1037419

55. Zhao N, Zhou G. Social media use and mental health during the COVID-19 pandemic: moderator role of disaster stressor and mediator role of negative affect. Appl Psychol Health Well Being. 2020;12(4):1019-1038. doi:10.1111/aphw.12226

56. Cheikh Ismail L, Mohamad MN, Bataineh MF, et al. Impact of the coronavirus pandemic (COVID-19) lockdown on mental health and well-being in the United Arab Emirates. Front Psychiatry. 2021;12:265. doi:10.3389/fpsyt.2021.633230

57. Ali KF, Whitebridge S, Jamal MH, Alsafy M, Atkin SL. Perceptions, knowledge, and behaviors related to COVID-19 among social media users: cross-sectional study. J Med Internet Res. 2020;22(9):e19913. doi:10.2196/19913

58. Bathina KC, Ten Thij M, Valdez D, Rutter LA, Bollen J. Declining well-being during the COVID-19 pandemic reveals US social inequities. PLoS One. 2021;16(7):e0254114. doi:10.1371/journal.pone.0254114

59. Abo-Ali EA, Al-Rubaki S, Lubbad S, et al. Mental well-being and self-efficacy of healthcare workers in Saudi Arabia during the COVID-19 pandemic. Risk Manag Healthc Policy. 2021;14:3167-3177. doi:10.2147/RMHP.S320421

60. Wright HM, Griffin BJ, Shoji K, et al. Pandemic-related mental health risk among front line personnel. J Psychiatr Res. 2021;137:673-680. doi:10.1016/j.jpsychires.2020.10.045

61. De Brier N, Stroobants S, Vandekerckhove P, De Buck E. Factors affecting mental health of health care workers during coronavirus disease outbreaks (SARS, MERS \& COVID-19): a rapid systematic review. PLoS One. 2020;15(12):e0244052. doi:10.1371/journal.pone.0244052

62. Saddik B, Elbarazi I, Temsah MH, et al. Psychological distress and anxiety levels among health care workers at the height of the COVID-19 pandemic in the United Arab Emirates. Int J Public Health. 2021;66:1604369. doi:10.3389/ijph.2021.1604369

63. Ajab S, Ádam B, Al Hammadi M, et al. Occupational health of frontline healthcare workers in the United Arab Emirates during the COVID-19 pandemic: a snapshot of summer 2020. Int J Environ Res Public Health. 2021;18(21):11410. doi:10.3390/ijerph182111410

64. González-Padilla DA, Tortolero-Blanco L. Social media influence in the COVID-19 Pandemic. Int Braz J Urol. 2020;46:120-124.

65. Chew C, Eysenbach G. Pandemics in the age of Twitter: content analysis of Tweets during the 2009 H1N1 outbreak. PLoS One. 2010;5(11):e14118. doi:10.1371/journal.pone.0014118

66. Del Rio C, Guarner J. The 2009 influenza A (H1N1) pandemic: what have we learned in the past 6 months. Trans Am Clin Climatol Assoc. 2010;121:128-140.

67. Chaabane S, Chaabna K, Abraham A, Mamtani R, Cheema S. Physical activity and sedentary behaviour in the Middle East and North Africa: an overview of systematic reviews and meta-analysis. Sci Rep. 2020;10(1):9363. doi:10.1038/s41598-020-66163-x

68. Bhanot D, Singh T, Verma SK, Sharad S. Stigma and discrimination during COVID-19 pandemic. Front Public Health. 2020;8:577018. doi:10.3389/fpubh.2020.577018

69. Xu J, Sun G, Cao W, et al. Stigma, discrimination, and hate crimes in Chinese-speaking world amid Covid-19 pandemic. Asian Journal of Criminology. 2021;16(1):51-74. doi:10.1007/s11417-020-09339-8

70. Al-Hosani F, Al-Mazrouei S, Al-Memari S, Al-Yafei Z, Paulo MS, Koornneef E. A review of COVID-19 mass testing in the United Arab Emirates. Front Public Health. 2021;9:528. doi:10.3389/fpubh.2021.661134

Journal of Multidisciplinary Healthcare

Dovepress

\section{Publish your work in this journal}

The Journal of Multidisciplinary Healthcare is an international, peer-reviewed open-access journal that aims to represent and publish research in healthcare areas delivered by practitioners of different disciplines. This includes studies and reviews conducted by multidisciplinary teams as well as research which evaluates the results or conduct of such teams or healthcare processes in general. The journal covers a very wide range of areas and welcomes submissions from practitioners at all levels, from all over the world. The manuscript management system is completely online and includes a very quick and fair peer-review system. Visit http://www.dovepress.com/testimonials.php to read real quotes from published authors.

Submit your manuscript here: https://www.dovepress.com/journal-of-inflammation-research-journal

Journal of Multidisciplinary Healthcare 2022:15

$f y$ in $\rightarrow$ DovePress 